TẠP CHÍ KHOA HỌC ĐẠI HỌC TÂN TRÀO
Ittp://tckh.daihoctantrao.edu.vn/ 2354 - 1431

\title{
Hồ Chí Minh - người làm thay đổi lịch sử
}

Trịnh Quốc Việt $t^{a *}$

${ }^{a}$ Học viện Học Chính trị, Bộ Quốc phòng

*Email: trinhviettthcm@gmail.com

\section{Thông tin bài viết}

Ngày nhận bài:

10/02/2020

Ngày duyệt đăng:

$10 / 3 / 2020$

Tù khóa:

Hồ Chí Minh; thay đổi lịch

sủ; giải phóng con người.

\section{Tóm tắt}

Sự nghiệp vĩ đại của Chủ tịch Hồ Chí Minh gắn với đấu tranh loại bỏ chủ nghĩa thực dân kiểu cũ, giải phóng dân tộc, xác lập quyền sống trong hòa bình, tự do và giải phóng con người triệt để. Đó là những giá trị nhân văn cao đẹp, vĩnh hằng, phản ánh tầm vóc tư tưởng, đạo đức, phong cách của một trong những vĩ nhân làm thay đổi lịch sử của thời đại.

\section{1. Đặt vấn đề}

Hiện nay, Nhân dân Việt Nam và nhân loại đều ghi nhận công lao to lớn của Hồ Chí Minh - một con người đã trở thành huyền thoại ngay khi còn sống. Con người đó đã tạo dựng nên những điều thần kỳ, và xác lập những giá trị không những cho thế kỉ $\mathrm{XX}$, mà còn cho các thế hệ mai sau. Giôn Tác man - Nguyên Chủ tịch Ủy ban Viện trợ thuốc men của Thụy Điển cho Việt Nam đã viết: "Cụ Hồ Chí Minh thuộc về tương lai, vì Cụ đã tạo ra tương lai vĩ đại ấy...”"44. Những giá trị nổi bật mà Hồ Chí Minh tạo dựng xuyên suốt sự nghiệp vĩ đại của mình, đã làm thay đổi lịch sử của dân tộc và nhân loại. Cống hiến trọn đời cho sứ mệnh vẻ vang đó đã làm nên tên tuổi của một nhà cách mạng, một chính khách, một nhân vật tiêu biểu của thời đại như GS Lászlo Salgo người Hungari khẳng định: "Ngày nay, trong phong trào cộng sản, không có nhân vật lịch sử nào có tầm vóc có thể so sánh được với Hồ Chí Minh. Đó là tầm vóc của một con người có phẩm giá mà tên gọi gợi lên một lòng

${ }^{44}$ Hồ Chí Minh - Một người châu Á của mọi thời đại, Nxb Chính trị quốc gia, Hà Nội, 2010, tr.404. kính trọng bất di bất dịch của không những bè bạn mà cả những đối thủ của Người”45.

\section{Nội dung}

2.1. Hồ Chí Minh - chiến sĩ quốc tế tiêu biểu trong đấu tranh loại bỏ chủ nghĩa thục dân kiểu cũ

Nguyễn Tất Thành với tên gọi Văn Ba rời cảng Nhà Rồng đến Pháp trên con tàu Amiran Latusơ Tơrêvin ngày 05/6/1911. Từ năm 1912 - 1917, Người đến nhiều nước ở châu Á, châu Âu, châu Phi và Mỹ latinh, sống hoà mình với nhân dân lao động các nước. Qua thực tiễn, Người cảm thông sâu sắc với cuộc sống khổ cực của nhân dân lao động ở các dân tộc thuộc địa cũng như nguyện vọng thiêng liêng của họ. Năm 1919, lấy tên là Nguyễn Ái Quốc, thay mặt những người Việt Nam yêu nước tại Pháp, Hồ Chí Minh đã gửi tới Hội nghị Vécxây (Versailles) bản yêu sách đòi quyền tự do cho nhân dân Việt Nam và cũng là quyền tự do cho nhân dân các nước thuộc địa.

\footnotetext{
${ }^{45}$ Thành Duy, Vi Quang Thọ và Nguyễn Xuân Dũng, Thế giới còn đổi thay nhưng tu tướng Hồ Chí Minh sống mãi, Nxb Khoa học xã hội, Hà Nội, 2008, tr.138.
} 
Dưới ảnh hưởng của Cách mạng Tháng Mười Nga năm 1917 và So thảo lần thứ nhất nhũng luận cương của V.I.Lênin về vấn đề dân tộc và thuộc địa, tháng 12/1920, Nguyễn Ái Quốc tham dự Đại hội lần thứ XVIII Đảng Xã hội Pháp và bỏ phiếu tán thành Đảng gia nhập Quốc tế III (Quốc tế Cộng sản), trở thành một trong những người sáng lập Đảng Cộng sản Pháp. Từ một người yêu nước trở thành một người cộng sản, Hồ Chí Minh khẳng định: "Muốn cứu nước và giải phóng dân tộc, không có con đường nào khác con đường cách mạng vô sản"46. Từ đó, Người không ngừng tố cáo, lên án tội ác man rợ của chủ nghĩa thực dân kiểu cũ với nhân dân các nước thuộc địa.

Năm 1921, cùng với một số người yêu nước của các thuộc địa Pháp, Nguyễn Ái Quốc tham gia sáng lập Hội Liên hiệp các dân tộc thuộc địa. Chính Người đã sáng lập Báo Người cùng khổ (Le Paria - 4/1922) nhằm đoàn kết, tổ chức và hướng dẫn phong trào đấu tranh giải phóng dân tộc ở các nước thuộc địa. Nhiều bài báo của Nguyễn Ái Quốc đã được đưa vào tác phẩm Bản án chế độ thục dân Pháp, xuất bản tại Paris năm 1925. Đây là một công trình nghiên cứu về bản chất của chủ nghĩa thực dân, góp phần thức tỉnh và cổ vũ nhân dân các nước thuộc địa đứng lên tự giải phóng. Bản án chế độ thục dân Pháp ra đời đã giáng đòn tiến công quyết liệt vào chủ nghĩa đế quốc, trước hết là đế quốc Pháp, vạch ra con đường cách mạng và tương lai tươi sáng cho các dân tộc bị áp bức. Đây là một cống hiến quan trọng của Nguyễn Ái Quốc đối với phong trào giải phóng dân tộc trên thế giới, góp phần tích cực vào việc truyền bá chủ nghĩa Mác Lênin vào Việt Nam và các nước thuộc địa khác ${ }^{47}$.

Tháng 6/1923, Nguyễn Ái Quốc từ Pháp sang Liên Xô, làm việc tại Quốc tế Cộng sản. Tại các đại hội của công hội, nông hội, thanh niên... Nguyễn Ái Quốc kiên trì bảo vệ và phát triển sáng tạo tư tưởng của V.I.Lênin về vấn đề dân tộc và thuộc địa, hướng sự quan tâm của Quốc tế Cộng sản tới phong trào giải phóng dân tộc. Tháng 11/1924, với tư cách là Uỷ viên Ban Phương Đông, Quốc tế Cộng sản và Uỷ viên Đoàn Chủ tịch Quốc tế Nông dân, Nguyễn Ái Quốc đến Quảng Châu (Trung Quốc) và làm việc trong đoàn cố vấn Bôrôđin của Liên Xô bên cạnh Chính phủ Tôn Dật Tiên.

Năm 1925, Nguyễn Ái Quốc thành lập Hội Việt Nam Cách mạng Thanh niên, trực tiếp mở lớp huấn

${ }^{46}$ Hồ Chí Minh, Toàn tập, Nxb Chính trị quốc gia, Hà Nội, 2011, tập 12 , tr.30.

${ }^{47}$ Hồ Chí Minh, Toàn tập, Sđd, tập 2, tr.594. luyện đào tạo cán bộ cách mạng, ra tuần báo “Thanh niên”, tờ báo cách mạng đầu tiên của Việt Nam nhằm truyền bá chủ nghĩa Mác - Lênin về Việt Nam, chuẩn bị cho việc thành lập Đảng Cộng sản Việt Nam. Các bài giảng của Nguyễn Ái Quốc tại các lớp huấn luyện được tập hợp in thành sách "Đường Kách mệnh" - một văn kiện lý luận quan trọng đặt cơ sở tư tưởng cho đường lối cách mạng Việt Nam.

Từ giữa năm 1927 cho đến khi trở thành Chủ tịch nước Việt Nam Dân chủ Cộng hòa (9/1945), Hồ Chí Minh dành phần lớn tâm trí của mình cho việc đấu tranh loại bỏ chủ nghĩa thực dân kiểu cũ ở Việt Nam và trên thế giới. Người đã không ngừng phê phán, lên án và tố cáo đanh thép tội ác của chủ nghĩa thực dân, chúng chà đạp lên nhân phẩm, vi phạm quyền con người một cách trắng trợn, phi nhân tính. Người chỉ rõ, dưới ách đô hộ của thực dân Pháp thì Việt Nam biến thành một địa ngục. Tính chất tùy tiện của pháp luật thực dân và phong kiến đã gây ra những tội ác man rợ, tàn khốc mà Hồ Chí Minh đã từng chứng kiến. Người so sánh và khẳng định những tội ác mà chế độ thực dân gây ra ở Đông Dương, Châu Á, Châu Phi, Mỹ La tinh là vô cùng dã man, tàn bạo hơn cả thời trung cổ. Vì vậy, suốt cuộc đời mình, Hồ Chí Minh là hiện thân của một chiến sĩ quốc tế tiêu biểu trong đấu tranh loại bỏ chủ nghĩa thực dân kiểu cũ trên toàn thế giới. Nói về điều này, R. Arixmenđi - Nguyên Tổng Bí thư Đảng Cộng sản Urugoay khẳng định: "Đồng chí Hồ Chí Minh là một trong những hình ảnh thân yêu nhất của phong trào cộng sản quốc tế, đồng chí là tượng trưng cho khối đoàn kết của chủ nghĩa xã hội và cuộc đấu tranh giải phóng dân tộc của các nước trên toàn thế giới" ${ }^{48}$.

\subsection{Hồ Chí Minh - hiện thân cho khát vọng tụ̂ do}

Đấu tranh cho quyền tự do của dân tộc cũng như nhân loại là tâm nguyện đi suốt hành trình vĩ đại của Hồ Chí Minh. Sau khi chiến tranh thế giới lần thứ nhất kết thúc, ngày 28 tháng 6 năm 1919, các nước thắng trận và bại trận đã họp Hội nghị tại Versailles, Pháp, để ký kết các hòa ước chính thức, cũng như phân chia các quyền lợi cho các nước thắng trận. Khi đó người thanh niên yêu nước Nguyễn Ái Quốc đang hoạt động ở Pháp, và Người đã thay mặt những người Việt Nam yêu nước gửi tới Hội nghị Versailles "Bản yêu sách của nhân dân An Nam". "Bản yêu sách" này bao gồm 8 điểm rất ôn hòa, yêu cầu Chính phủ Pháp trao trả một số quyền tự do, dân chủ cơ bản cho nhân dân Việt

\footnotetext{
${ }^{48}$ Hồ Chí Minh - Một người châu Á của mọi thời đại, Sđd, tr.50
} 
Nam. Nhưng tất cả những yêu sách ôn hòa đó của Nhóm người Việt Nam yêu nước do Nguyễn Ái Quốc thay mặt ký tên đều không được Chính phủ Pháp, cũng như các nước trong Hội nghị Versailles quan tâm. Từ đó, Nguyễn Ái Quốc rút ra kết luận quan trọng rằng "Vận dụng công thức của Các Mác, chúng tôi xin nói với anh em rằng, công cuộc giải phóng anh em chỉ có thể thực hiện được bằng sự nỗ lực của bản thân anh em"49.

Khát vọng về một cuộc sống tự do, ở một nước tự do ở Hồ Chí Minh được hun đúc từ chính những trải nghiệm đầy đau thương trên quê hương mình, cũng như trong hành trình bôn ba tìm đường cứu nước qua nhiều châu lục. Khát vọng đó được Người nhấn mạnh trong Dự thảo Điều lệ Đảng ở Quảng Châu, Trung Quốc năm 1925: "Đêm nay, tôi xin thề gia nhập chi bộ này để hoạt động a) vì tự do cho đồng bào tôi, b) vì hạnh phúc cho những người nông dân bị áp bức; vì mục đích này, trước hết tôi tham gia lật đổ các quốc gia đế quốc chủ nghĩa và xâm lược nhằm lập nền tự trị cho đất nước; sau đó, tôi sẽ chiến đấu chống lại sự phân biệt giai cấp xã hội và tham gia vào cách mạng thế giới, đó là mục tiêu cuối cùng chúng ta theo đuổi”, ${ }^{50}$.

Khát vọng cho tự do còn được Hồ Chí Minh khẳng định trong Lời tuyên thệ nhậm chức ngày 2/3/1946: "Chúng tôi, Chính phủ kháng chiến nước Việt Nam Dân chủ Cộng hòa, Tối cao cố vấn đoàn và Ủy viên kháng chiến hội, trước bàn thờ thiêng liêng của Tổ quốc, trước Quốc hội, thề xin cương quyết lãnh đạo nhân dân kháng chiến, thực hiện nền dân chủ cộng hòa Việt Nam, mang lại tự do hạnh phúc cho dân tộc" $"$ 1. Sau này, Hồ Chí Minh đã đúc kết thành chân lý "Không có gì quý hơn độc lập, tự do". Chân lý ấy không chỉ trở thành động lực thôi thúc mọi người dân Việt Nam trong đấu tranh giành quyền tự $\mathrm{do}$, mà còn trở thành chân lý của thời đại, thúc đẩy các dân tộc trên thế giới đoàn kết, đấu tranh vì cuộc sống tự do và hạnh phúc. Chân lý đó đã trở thành tư duy và hành động nhất quán của Hồ Chí Minh, bởi lẽ, Người không chỉ đấu tranh cho tự do cho dân tộc mình, mà còn cho tự do của nhân loại. Đại tướng Võ Nguyên Giáp đã nhấn mạnh trong lời kết luận Hội thảo khoa học kỷ niệm 100 năm ngày sinh Chủ tịch Hồ Chí Minh ở Hà Nội: "Người được coi là một chiến sĩ đi tiên phong trong việc

\footnotetext{
${ }^{49}$ Hồ Chí Minh, Toàn tập, Sđd, tập 2, tr.138.

${ }^{50}$ Hồ Chí Minh, Toàn tâp, Sđd, tập 2, tr.497.

${ }^{51}$ Hồ Chí Minh, Toàn tập, Sđd, tập 4, tr.223.
}

thức tỉnh dân tộc mình và các dân tộc bị áp bức vùng lên đấu tranh cho độc lập tự do"52.

\subsection{Hồ Chí Minh - biểu trung cho khát vọng hòa bình}

Con đường cách mạng mà Hồ Chí Minh đã tìm ra cho dân tộc Việt Nam, là con đường đi từ độc lập dân tộc đến một thế giới hoà bình và phát triển. Với phương châm đó, Người luôn tìm những giá trị mang tính phổ quát là những nguyên tắc đạo đức, là lòng nhân, là tính thiện, là tình yêu tự do, là khát vọng sống trong độc lập tự do mà trước hết là dân tộc mình. Người đã từng nhận xét: "Tuy phong tục mỗi dân mỗi khác, nhưng có một điều thì dân nào cũng giống nhau. Áy là dân nào cũng ưa sự lành ghét sự dữ ${ }^{353}$.

Với đối phương, những luận điểm của Hồ Chí Minh cũng đầy tính thuyết phục: "Các bạn yêu nước Pháp của các bạn và muốn nó độc lập... Nhưng chúng tôi cũng phải được phép yêu nước của chúng tôi và muốn nó độc lập chứ... Cái mà các bạn coi là lý tưởng cũng phải là lý tưởng của chúng tôi” ${ }^{54}$. Cuộc kháng chiến kiên cường của nhân dân Việt Nam là cuộc chiến đấu vì hòa bình, tiến bộ và sự phát triển. Đó là cuộc chiến đấu chính nghĩa mang những ý nghĩa nhân văn sâu sắc, bảo vệ những giá trị thiêng liêng trong lương tâm của nhân loại, nên nó đã nhận được sự ủng hộ rộng lớn của loài người tiến bộ. Đã hình thành mặt trận rộng rãi của nhân dân thế giới ủng hộ cuộc chiến đấu của nhân dân Việt Nam, trong đó có cả nhân dân Pháp và nhân dân Mỹ.

Trong bất cứ hoàn cảnh nào, Hồ Chí Minh luôn kiên trì tìm giải pháp tối ưu nhất để đem lại hoà bình cho nhân dân, cho đất nước Việt Nam. Với mục tiêu hoà bình, Hồ Chí Minh hướng đến điều hoà sự đa dạng về xu hướng chính trị, chế độ xã hội giữa các quốc gia, để các dân tộc gần gũi nhau, hiểu biết nhau, để mở rộng sự hợp tác hữu nghị giữa nhân dân Việt Nam và nhân dân các quốc gia trên thế giới, đặc biệt là với các nước láng giềng và khu vực, để tăng thêm sức mạnh của các dân tộc thuộc địa và phụ thuộc trong cuộc đấu tranh chống chủ nghĩa thực dân cũ và mới, hướng tới hoà bình và thịnh vượng. Ngày 25/6/1955, khi đến sân bay Bắc Kinh, Người phát biểu: "Nhân dân Việt Nam tin chắc rằng mọi sự phân tranh trên thế giới đều có thể giải quyết bằng cách hoà bình; tin chắc rằng các nước dù

\footnotetext{
${ }^{52}$ Thành Duy, Vi Quang Thọ và Nguyễn Xuân Dũng, Thế giới còn đổi thay nhưng tư tương Hồ Chi Minh sống mãi, Sđd, tr.914.

${ }^{53}$ Hồ Chí Minh, Toàn tập, Sđd, tập 4, tr.397.

${ }^{54}$ Hồ Chí Minh, Toàn tập, Sđd, tập 4, tr.75.
} 
chế độ xã hội khác nhau và hình thái ý thức khác nhau cũng đều có thể chung sống hoà bình được" $" 55$.

Nhằm dựng xây nền hoà bình chân chính và bền vững, Hồ Chí Minh cho rằng cuộc đấu tranh vì quyền dân tộc cơ bản, vì sự bình đẳng thực sự giữa các dân tộc cũng là cuộc đấu tranh vì một trật tự thế giới mới với lối ứng xử hoà bình trong quan hệ quốc tế, vì hoà bình không thể tách khỏi độc lập thật sự. Tư tưởng đấu tranh cho hòa bình cùng với hoạt động không mệt mỏi suốt cuộc đời của Người vì hòa bình, độc lập, dân chủ, vì con người nhận được sự ủng hộ của cả loài người tiến bộ. Cho đến khi để lại những dòng tâm huyết nhất trong bản $D i$ chúc lịch sử, Người viết: "Điều mong muốn cuối cùng của tôi là: Toàn Đảng, toàn dân ta đoàn kết phấn đấu, xây dựng một nước Việt Nam hoà bình, thống nhất, độc lập, dân chủ và giàu mạnh, và góp phần xứng đáng vào sự nghiệp cách mạng thế giới" "56. Hans D'Orville, Phó Tổng giám đốc Tổ chức Giáo dục, Khoa học và Văn hóa Liên hợp quốc (UNESCO) đã có bài tham luận đặc biệt đánh giá về Hồ Chí Minh tại hội thảo quốc tế kỷ niệm 120 năm ngày sinh của Người ở Paris, Pháp, trong đó có nhấn mạnh: "Chủ tịch Hồ Chí Minh là người lãnh đạo cuộc đấu tranh của Việt Nam để giành tự do và độc lập dân tộc. Đối với những người Việt Nam và các dân tộc trên thế giới, trước tiên đó là một con người của hòa bình và của sự hòa giải vì phải công nhận rằng Hồ Chí Minh đã luôn luôn đấu tranh cho sự phát triển của đất nước, của khu vực và trên thế giới" ${ }^{\text {"57 }}$. Rõ ràng tư tưởng hoà bình Hồ Chí Minh tiêu biểu cho khát vọng hoà bình của cả dân tộc Việt Nam và nhân loại tiến bộ. Điều đó, không chỉ đúng với thời gian Người còn sống mà còn soi sáng đến tương lai, nhất là khi nhân loại đang cần chung tay đẩy lùi các hệ lụy của toàn cầu hóa như: Biến đổi khí hậu, thiên tai, dịch bệnh, nạn đói, thất học, xung đột dân tộc, sắc tộc, chủ nghĩa khủng bố,...

2.4. Hồ Chí Minh - trọn đời đấu tranh giải phóng con ngưò̀i

Khi nói về quyền con người, Hồ Chí Minh đã đề cập đến quyền tự nhiên của con người được khẳng định trong Tuyên ngôn độc lập năm 1776 của nước Mỹ, Tuyên ngôn nhân quyền và quyền công dân của Cách mạng tư sản Pháp năm 1789. Tuy vậy, không dừng lại ở các quyền tự nhiên của con người được đề cập ở hai bản tuyên ngôn trên, Hồ Chí Minh đã tiếp

\footnotetext{
${ }^{55}$ Hồ Chí Minh, Toàn tập, Sđd, tập 10, tr.12.

${ }^{56}$ Hồ Chí Minh, Toàn tập, Sđd, tập 15, tr.624.

57 https://www.vietnamplus.vn/tu-tuong-ho-chi-minh-van-giu-gia-tri-
} thoi-dai/46979.vnp thu, phát triển từ quyền con người thành quyền dân tộc tự quyết trong thời đại mà các dân tộc thuộc địa, lệ thuộc đang vùng lên đấu tranh giành quyền độc lập dân tộc. Ngay ở phần đầu tiên trong Tuyên ngôn độc lập của Việt Nam, Hồ Chí Minh trích dẫn: “Tất cả mọi người đều sinh ra bình đẳng. Tạo hóa cho họ những quyền không ai có thể xâm phạm được, trong những quyền ấy, có quyền được sống, quyền tự do và quyền mưu cầu hạnh phúc" ${ }^{\text {" }}$. Từ đây, Người khẳng định: "Suy rộng ra, câu ấy có ý nghĩa là: Tất cả các dân tộc trên thế giới đều sinh ra bình đẳng; dân tộc nào cũng có quyền sống, quyền sung sướng và quyền tự do" $" 59$. Và Người tiếp tục nhấn mạnh điều đó bằng trích dẫn Tuyên ngôn Nhân quyền và quyền công dân của Cách mạng Pháp năm 1789: "Người ta sinh ra tự do và bình đẳng về quyền lợi, và phải luôn luôn được tự do và bình đẳng về quyền lợi”. Theo Người "Đó là những lẽ phải không ai chối cãi được".

Trong phiên họp đầu tiên của Chính phủ lâm thời, Hồ Chí Minh đã đề ra những nhiệm vụ cấp bách của cách mạng, trong đó ban hành Hiến pháp là một nhiệm vụ cấp bách để bảo đảm quyền tự do, dân chủ nhằm thực thi quyền con người của Nhân dân ta, thực hiện nam nữ bình quyền, không phân biệt giai cấp, tôn giáo...

Với tâm nguyện luôn vì con người, Hồ Chí Minh thường nhắc nhở cán bộ, đảng viên phải hiểu rõ: "Chế độ ta là chế độ dân chủ. Tức là nhân dân làm chủ. Tức là cán bộ và nhân viên từ cấp trên đến cấp dưới đều là đầy tớ của nhân dân, đều phải một lòng một dạ phục vụ nhân dân" ${ }^{\circ 0}$. Đây cũng chính là động cơ giải phóng triệt để con người mà Hồ Chí Minh luôn ấp ủ, đó là một động cơ hết sức trong sáng, cao cả và đầy tính nhân văn cộng sản. Với Người mục đích xây dựng chủ nghĩa xã hội là mang đến cho con người những điều tốt đẹp nhất: "làm cho mọi người dân được ấm no, hạnh phúc và học hành tiến bộ" "61 .

Cho đến cuối cuộc đời, trong "Di chúc" để lại cho hậu thế, Hồ Chí Minh tiếp tục khẳng định tư tưởng nền gốc ấy. Đoạn mở đầu "Di chúc", Người viết: "Đầu tiên là công việc đối với con người" $"$ "Tổng kết lại toàn bộ quá trình hoạt động cách mạng của mình, Người chỉ tiếc không còn được phục vụ nhân dân lâu hơn nữa.

\footnotetext{
${ }^{58}$ Tuyên ngôn độc lập 1945 và các Hiến pháp Việt Nam (1946, 1959, 1980, 1992, 2013), Nxb CTQG, Hà Nội, 2015, tr.12.

${ }^{59}$ Tuyên ngôn độc lập 1945 và các Hiến pháp Việt Nam (1946, 1959 1980, 1992, 2013), Sđd, tr.7.

${ }^{60}$ Hồ Chí Minh, Toàn tập, Sđd, tập 13, tr.10.

${ }^{61}$ Hồ Chí Minh, Toàn tập, Sđd, tập 12, tr.521.

${ }^{62}$ Hồ Chí Minh, Toàn tập, Sđd, tập 15, tr.616.
} 
Toàn bộ cuộc đời và sự nghiệp cách mạng vĩ đại của Hồ Chí Minh là vì con người, nhằm giải phóng con người khỏi mọi áp bức, bóc lột, bất công. Ở Hồ Chí Minh, sự nghiệp đấu tranh giải phóng dân tộc không tách rời sự nghiệp đấu tranh giải phóng con người. Đó cũng là sự nghiệp đấu tranh vì hoà bình, hữu nghị giữa các dân tộc, nhằm mục tiêu giải phóng toàn nhân loại. Điều này được cố Thủ tướng Phạm Văn Đồng khẳng định: “Trong luận điểm về cách mạng của Hồ Chí Minh, trung tâm là luận điểm về con người... Mục tiêu, cứu cánh, phương tiện và động lực đều ở trong mỗi con người... tất cả đều bắt đầu từ con người và con người làm ra tất cả. Hồ Chí Minh luôn quán triệt chân lý: Cách mạng là sự nghiệp của nhân dân, do nhân dân và vì nhân dân" ${ }^{\text {"63 }}$. Dưới góc nhìn của Philippe Devillers - nhà báo, nhà sử học Pháp trong tác phẩm Paris - Sài Gòn - Hà Nội đề cập: "Tôi nghĩ Hồ Chí Minh là một nhà tư tưởng tiên tiến, thông thái, là người đưa đường chỉ lối tuyệt vời. Nét nổi bật trong tư tưởng Hồ Chí Minh là chủ nghĩa nhân đạo: Nó đáp ứng nhu cầu cụ thể của con người và cuộc sống hàng ngày của họ" "64.

\section{Kết luận}

Hồ Chí Minh chính là hiện thân của những giá trị cao quý nhất của dân tộc Việt Nam, biểu trưng cho các giá trị tiêu biểu không chỉ của dân tộc mà trên bình diện thời đại. Con người đó đã tạo ra và làm nên những điều phi thường và chính những điều phi thường đó đã thay đổi lịch sử, làm cho lịch sử dân tộc và nhân loại trở về đúng với quỹ đạo đầy ắp những giá trị của con người, do con người và vì con người. $\mathrm{TS}$ Madagat Ahmed - Giám đốc UNESCO khu vực châu Á - Thái Bình Dương nêu rõ trong lời kết của bài tham luận hội thảo quốc tế kỷ niệm 100 năm ngày sinh của Chủ tịch Hồ Chí Minh về cống hiến của Người với dân tộc và nhân loại: "Người sẽ được ghi nhớ không phải chỉ là người giải phóng cho Tổ quốc và nhân dân bị đô hộ, mà còn là một nhà hiền triết hiện đại đã mang lại một viễn cảnh và hy vọng mới cho những người đang đấu tranh không khoan nhượng để loại bỏ bất công, bất bình đẳng khỏi trái đất này" ${ }^{\text {65 }}$. Điều này cũng được Sêraphin Quysơn nhấn mạnh: "Khó có thể có được một người châu Á khác như Người ở thời đại chúng ta cũng như trong các thế hệ mai sau. Người thực sự là một người châu Á của tất cả các thời đại với ý nghĩa đầy đủ nhất của nó" ${ }^{\circ 6}$.

Thế giới chúng ta đang sống đang đứng trước những thử thách nghiêm trọng do tác động mặt trái của quá trình toàn cầu hóa. Trong kỷ nguyên của Cách mạng công nghiệp 4.0 với Internet kết nối vạn vật, không ít người lầm tưởng về một thế giới phẳng - nơi mà con người đã hoàn toàn được sống tự do, hạnh phúc. Tuy nhiên, những giá trị nền tảng của quyền con người, quyền dân tộc tự quyết, quyền sống trong tự do, độc lập, hòa bình vẫn là khát vọng chưa trở thành hiện thực ở nhiều quốc gia, dân tộc trên thế giới. Điều đó cho thấy những cống hiến vĩ đại của Hồ Chí Minh cho dân tộc và nhân loại trong thế kỉ XX vẫn có giá trị thời sự và định hướng cho tương lai tươi sáng của nhân loại như Stanley Karnow khẳng định: "Hồ Chí Minh - người mang lại ánh sáng"67

\section{TÀI LIỆU THAM KHẢO}

1. Phạm Văn Đồng (1991), Hồ Chủ tịch - một con ngươi, một dân tộc, một thờ đại, một sụ nghiệp, Nxb Sự thật, Hà Nội.

2. Hồ Chí Minh (2011), Toàn tập, Nxb Chính trị quốc gia - Sự thật, Hà Nội.

3. Tuyên ngôn độc lập 1945 và các Hiến pháp Việt Nam (1946, 1959, 1980, 1992, 2013) (2015), Nxb Chính trị quốc gia - Sự thật, Hà Nội.

4. Thành Duy, Vi Quang Thọ và Nguyễn Xuân Dũng, Thế giới còn đổi thay nhưng tư tưởng Hồ Chí Minh sống mãi (2008), Nxb Khoa học xã hội, Hà Nội.

5. Hồ Chí Minh - Một người châu Á của mọi thời đại (2010), Nxb Chính trị quốc gia, Hà Nội.

6. Song Thành (2010), Hồ Chí Minh - nhà văn hóa kiệt xuất, Nxb Chính trị quốc gia, Hà Nội.

7. Hồ Chí Minh - người mang lại ánh sang (2011), Nxb Thời đại - Tạp chí Xưa và Nay, Hà Nội.

\footnotetext{
${ }^{63}$ Phạm Văn Đồng, Hồ Chủ tịch - một con người, một dân tộc, một thờ đại, một sự nghiệp, Nxb Sự thật, Hà Nội, 1991, tr.28.

${ }^{64}$ Dẫn theoSong Thành, Hồ Chi Minh - nhà văn hóa kiệt xuất, Nxb Chính trị quốc gia, Hà Nội, 2010, tr.361.

${ }^{65}$ Thành Duy, Vi Quang Thọ và Nguyễn Xuân Dũng (2008), Thế giói còn đổi thay nhưng tu tưởng Hồ Chí Minh sống mãi (2008), Nxb Khoa học xã hội, Hà Nội, tr.79.

${ }^{66}$ Hồ Chí Minh - Một người châu Á của mọi thời đại (2010), Nxb Chính trị quốc gia, Hà Nội, tr.359.

${ }^{67}$ Hồ Chí Minh - người mang lại ánh sáng, Nxb Thời đại - Tạp chí Xưa và Nay, Hà Nội, 2011, tr.8.
} 92 


\section{Ho Chi Minh - who makes changing history}

Trinh Quoc Viet

\section{Article info}

Recieved:

10/02/2020

Accepted:

$10 / 3 / 2020$

Keywords:

Ho Chi Minh; change

history; freeing people.

\begin{abstract}
The great career of Ho Chi Minh President was associated with the struggle to eliminate the old-style colonialism, liberate the nation, establish the right to live in peace, liberty and liberate people thoroughly. These are the values of beautifu and eternal humanity, reflecting the ideological stature, morality, and style of one of the great men who changed the history of the era.
\end{abstract}

